\title{
Crescimento de mudas de mamoeiro em condições controladas com água salina
}

\section{Growth of papaya under irrigation with saline water}

\author{
Débora C. Coelho ${ }^{1}$, Elaine C. B. Silva ${ }^{2}$, Franciédna Maria da Silva ${ }^{3}$ Eldon M. L. Sousa ${ }^{4}$, Reginaldo G. Nobre ${ }^{5}$
}

Resumo: Diante da importância socioeconômica e alimentar do mamoeiro para a região nordeste, onde naturalmente ocorrem águas com teores elevados de sais, objetivou-se avaliar o crescimento de mudas de mamoeiro em casa de vegetação sob irrigação com água salina. Neste sentido, foi realizado um experimento, em ambiente protegido da Universidade Federal de Campina Grande, UFCG, Campus de Pombal, PB onde foram estudados, cinco níveis de salinidade da água de irrigação em uma cultivar de mamoeiro (Tainung-1). O delineamento experimental foi inteiramente casualizado, sendo a unidade experimental composta por quatro plantas úteis; as mudas de mamoeiro foram formadas em sacolas plásticas de $500 \mathrm{ml}$ de volume; avaliou-se o crescimento e a massa seca da parte aérea das plantas. Sendo as variáveis submetidas ao teste F, e realizando análise de regressão polinomial para o fator salinidade da água. Sendo assim; A salinidade reduz o crescimento das mudas de mamoeiro; A altura de planta e diâmetro de caule foi afetado com o incremento unitário da salinidade da água; A variável que melhor expressa o efeito da salinidade nas mudas de mamoeiro é massa seca da parte aérea, por haver maior redução com aumento unitário da salinidade.

Palavras-chave: Carica papaya L., salinidade, condutividade.

Abstract: Given the socio-economic and dietary importance of papaya in the northeastern region, where waters with naturally high levels of salts occur, aimed to evaluate the growth of papaya seedlings in a greenhouse under irrigation with saline water. In this sense, an experiment was conducted under greenhouse conditions at the Federal University of Campina Grande, UFCG, Campus de Pombal, where PB were studied, five levels of salinity of irrigation water in a cultivar of papaya ( Tainung - 1 ). The experimental design was randomized, and the experimental unit consists of four useful plants ; the papaya seedlings were formed in plastic bags of $500 \mathrm{ml}$ volume; evaluated the growth and dry mass of the shoots. Being submitted to the variables Ftest, and performing analyzes of polynomial for the salinity of the water factor regression. Therefore; Salinity reduces growth of papaya seedlings; The plant height and stem diameter was affected with a unit increase in water salinity; The variable that best expresses the effect of salinity on papaya seedlings is dry mass of the aerial part, for having further reduction with unit increase in salinity.

Keywords: Carica papaya L., salinity, conductivity.

\footnotetext{
*Autor para correspondência

Recebido em 04/12/2014 e aceito em 04/02/2015

${ }^{1}$ Graduada em Agronomia - UFCG/CCTA /UATA, Campus Pombal PB - Rua Jairo Vieira Feitosa, n 1770, Bairro dos Pereiros, CEP: 58.840.000.

Email:debora.coelhoo@hotmail.com

${ }^{2}$ Graduada em Agronomia - UAGRA/CCTA/UFCG, Campus Pombal PB - Rua Jairo Vieira Feitosa, n 1770, Bairro dos Pereiros, CEP: 58.840.000. Email: elaineagronomia@gmail.com

${ }^{3}$ Graduada em Engenharia Ambiental. UFCG/CCTA/UACTA, Campus Pombal PB - Rua Jairo Vieira Feitosa, n 1770, Bairro dos Pereiros, CEP: 58.840.000. E-mail: Edna.ufcg@hotmail.com

${ }^{4}$ Graduando em Engenharia Ambiental da UAGRA/CCTA/UFCG, Campus Pombal PB - Rua Jairo Vieira Feitosa, n 1770, Bairro dos Pereiros, CEP:

58.840.000. E-mail: eldonmacio@hotmail.com

${ }^{5}$ Eng. Agrônomo, Dr. Agronomia, Professor UAGRA/CCTA/UFCG, Campus Pombal PB - Rua Jairo Vieira Feitosa, n 1770, Bairro dos Pereiros, CEP:

58.840.000. E-mail: rgomesnobre@ccta.ufcg.edu.br
} 


\section{INTRODUÇÃO}

O mamoeiro (Carica papaya L.) é uma planta frutífera originária da América do Sul, a qual foi posteriormente disseminada por todo o mundo tropical. Seu cultivo efetua-se em áreas com até $32^{\circ}$ de Latitude Norte ou Sul (LITZ, 1984; MEDINA, 1989).

O Brasil é o principal produtor mundial de mamão (FAO, 1991), tendo contribuído com 659.683 toneladas em 1989 (BRASIL, IBGE, 1991), o que deve-se principalmente à introdução de cultivares havaianas do grupo 'Solo' e de híbridos do grupo 'Formosa', especialmente nos Estados do Pará, Bahia e Espírito Santo (MARIN et aI., 1987).

O mamoeiro pode ser propagado vegetativamente, entretanto, a propagação por sementes é o processo mais prático e econômico utilizado pelos agricultores nos plantios comerciais (MEDINA, 1995). A utilização de sementes com alta qualidade genética, fisiológica, física e sanitária é um dos fatores importantes no sucesso de estabelecimento das culturas. A qualidade fisiológica das sementes é caracterizada, principalmente, pela sua germinação, vigor e longevidade (POPINIGIS, 1985).

De acordo com Maas \& Hoffman (1977), o efeito acumulativo dos sais no solo faz com que a disponibilidade de água para a cultura diminua à medida que a salinidade aumenta. Assim, a salinidade provoca alterações nos processos fisiológicos das culturas, com consequente redução no seu crescimento e na produtividade. $\mathrm{O}$ efeito da salinidade sobre o desenvolvimento das plantas é um assunto discutido em vários países, principalmente, nos que apresentam regiões áridas e semiáridas (RIBEIRO et al., 2009).

A utilização de água de baixa qualidade para a irrigação torna-se um fator limitante para a produção vegetal, uma vez que a salinidade inibe o crescimento das plantas, em função dos efeitos osmóticos e tóxicos dos íons (MUNNS, 2002). A salinidade afeta negativamente a absorção de água pelas raízes. A presença de sais na solução do solo acarreta em uma diminuição do potencial hídrico externo (EPSTEIN \& BLOOM, 2006).

A salinidade pode afetar as plantas devido a um desbalanço nutricional, em que o excesso de íons no solo, inibe a absorção de outros íons. Por exemplo, quando a concentração de $\mathrm{Na}$ e $\mathrm{Cl}$ no solo é alta, a absorção de nutrientes minerais como NO3, Ca e K são reduzidos (LARCHER, 2000). Outro efeito é a redução do acúmulo de fitomassa, o que reflete, também no custo metabólico de energia associado às adaptações ao estresse salino, incluindo também a síntese de solutos orgânicos para proteção de macromoléculas e osmorregulação, a regulação do transporte e distribuição iônica em vários órgãos e dentro das células e a manutenção da integridade das membranas celulares (WILLADINO \& CAMARA, 2004).

De acordo com Cavalcante et al. (2010), o acúmulo de $\mathrm{Na}$ e $\mathrm{Cl}$, em tecidos vegetais acarretam em toxicidade iônica devido a mudanças nas relações $\mathrm{Na} / \mathrm{K}, \mathrm{Na} / \mathrm{Ca}$ e $\mathrm{Cl} / \mathrm{NO}$, provocando desde reduções no desenvolvimento até morte das plantas.

Assim, objetivou-se avaliar o crescimento de mudas de mamoeiro, cultivadas em casa de vegetação sob irrigação com água salina.

\section{MATERIAL E MÉTODOS}

O experimento foi desenvolvido em ambiente protegido (casa de vegetação) do Centro de Ciências e Tecnologia Agroalimentar - CCTA da Universidade Federal de Campina Grande - UFCG, localizado no município de Pombal, Paraíba, $\mathrm{PB}$, nas coordenadas geográficas $6^{\circ} 47^{\prime} 20^{\prime \prime}$ de latitude S e $37^{\circ} 48^{\prime} 01^{\prime \prime}$ de longitude W, a uma altitude de $194 \mathrm{~m}$.

Em um delineamento experimental inteiramente casualizado, estudou-se, em esquema fatorial, cinco níveis de salinidade da água de irrigação ( $\mathrm{CEa})(\mathrm{S} 1=0,8 ; \mathrm{S} 2=1,6$; $\mathrm{S} 3=2,4 ; \mathrm{S} 4=3,2$ e $\mathrm{S} 5=4,0 \mathrm{dS} \mathrm{m}-1$ ), na cultivar de mamoeiro (Tainung-1). Unindo-se os fatores, tem-se como resultado 5 tratamentos (5 níveis de salinidade x 1 cultivar de mamoeiro), com a unidade experimental constituída por quatro plantas úteis.

A semeadura ocorreu em sacolas plásticas, com capacidade de $500 \mathrm{ml}$. As sementes, já devidamente selecionadas e tratadas com fungicida disulfato de thiram $(4 \mathrm{~g}$ $\mathrm{kg}-1$ de sementes), foram semeadas na razão de duas por sacolas, preenchidas com solo e esterco bovino curtido, com proporção de $80 \%$ de solo e $20 \%$ de esterco bovino, sendo o solo coletado do horizonte $\mathrm{A}$ de um Neossolo Flúvico não salino e não sódico.

Após a emergência, deixou desenvolver apenas uma seedling (pé-franco) por recipiente. Nesse processo de seleção, foram eliminadas as plântulas desuniformes.

A irrigação foi realizada apenas uma vez ao dia, no final da tarde com um volume uniforme de água às plantas.

Adotaram-se todos os demais cuidados de controle de ervas daninhas, prevenção e controle de pragas e doenças.

As águas de irrigação foram preparadas de modo a se ter uma proporção equivalente de 7:2:1, entre $\mathrm{Na}: \mathrm{Ca}: \mathrm{Mg}$, respectivamente, a partir dos sais $\mathrm{NaCl}, \mathrm{CaCl} 2.2 \mathrm{H} 2 \mathrm{O}$ e $\mathrm{MgCl} 2.6 \mathrm{H} 2 \mathrm{O}$.

Para tanto, no preparo da água de irrigação com vários níveis de salinidade, é considerada a relação entre CEa e concentração de sais $\left(10^{*} \mathrm{meq} \mathrm{L}-1=1 \mathrm{dS} \mathrm{m}-1\right.$ de CEa), extraída de Rhoades et al. (1992), válida para CEa de 0,1 a $5,0 \mathrm{dS}$ m-1 em que se enquadram os níveis testados, tendo como base a água de abastecimento existente no local. Após preparação, as águas foram armazenadas em recipientes plásticos de 60L, um para cada nível de CEa estudado, devidamente protegidos, evitando-se a evaporação, a entrada de água de chuva e a contaminação com materiais que pudessem comprometer sua qualidade. Para preparo das águas, com as devidas condutividades elétricas (CE), os sais foram pesados conforme tratamento, adicionando-se águas, até ser atingido o nível desejado de $\mathrm{CE}$, conferindo-se os valores com um condutivímetro portátil com ajuste de condutividade a temperatura de $25^{\circ} \mathrm{C}$.

Após 30 dias, iniciando-se depois de cinco dias após semeadura (DAS), foram mensurados a altura $(\mathrm{cm})$, o diâmetro do caule (mm) e o número de folhas. E após os 30 dias, realizou-se a retirada das mudas. $\mathrm{O}$ material coletado foi embalado e levado à estufa de circulação forçada de ar, onde ficou durante 48 horas para obtenção da massa seca, possibilitando a determinação da fitomassa da parte aérea do mamoeiro (MSPA) (g).

Os dados obtidos foram avaliados mediante análise de variância pelo teste ' $F$ '. Nos casos de significância, foi realizada análise de regressão polinomial (linear e quadrática) 
para o fator 'salinidade da água de irrigação' (FERREIRA 2000).

\section{RESULTADOS E DISCUSSÃO}

Verificou-se no (Gráfico 1) que a salinidade ocasionou efeito quadrático em relação ao número de folhas com aumento em $1 \mathrm{dS}$ m-1 na salinidade da água, com base no menor nível estudado (0,8 dS m-1). Observando que a melhor média foi encontrada na condutividade $1,6 \mathrm{dS}$ m-1 com aproximadamente 8,45 folhas. Deve-se salientar que a redução no número de folhas observado nas mudas de mamão, está relacionada ao menor crescimento efetivo em folhas ocasionado pela salinidade, não tendo ocorrido queda das folhas, embora algumas folhas apresentassem sintomas de fitotoxidez.

Silva et. al (2008) estudando o desenvolvimento e produção de duas cultivares de mamoneira sob estresse salino durante 80 dias verificou, que a salinidade da água de irrigação resultou em uma redução progressiva do número de folhas e os dados obtidos se ajustaram ao modelo linear, com decréscimos por aumento unitário da salinidade da água de irrigação de 9,9 e 7,5\% para as cultivares BRS Paraguaçu e Energia, respectivamente.

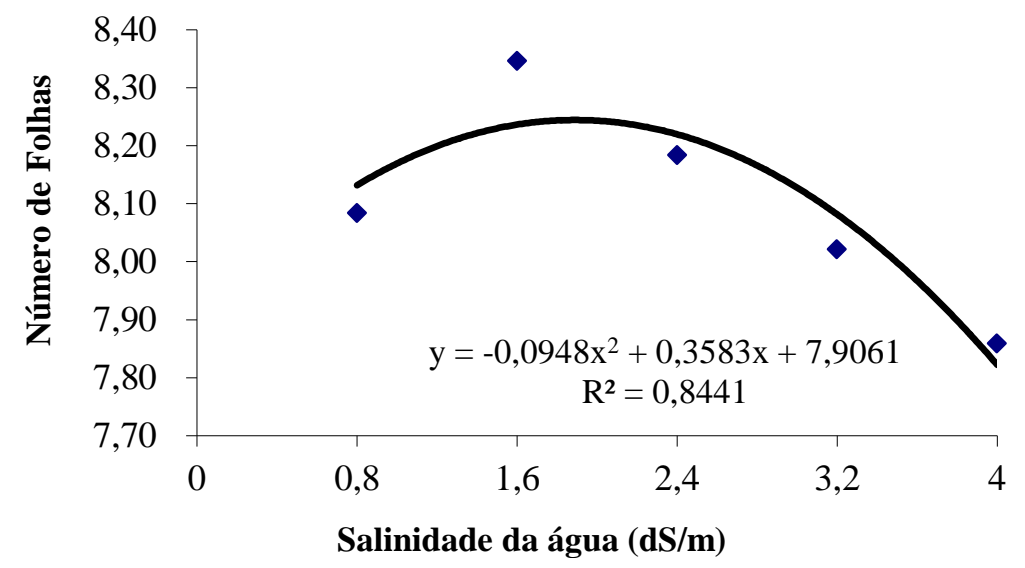

Figura 1: Número de folhas da média das mudas de mamoeiro estudados, aos 30 dias após semeadura sob salinidade da água de irrigação (dS m $\left.{ }^{-1}\right)$. Pombal, PB, 2013.

Em relação ao diâmetro de caule, observou-se que a salinidade ocasionou redução linear decrescente no diâmetro de caule das mudas de mamoeiro estudados (Figura 3), na ordem de 5,10\% com acréscimo em $1 \mathrm{dS}$ m-1 na salinidade da água utilizada na irrigação, comparado ao menor nível estudado (0,8 dS m-1), observando que a melhor média foi aproximadamente $4,6 \mathrm{~mm}$.

Estudando duas cultivares de mamoneira sob estresse salino por 80 e 100 dias Silva et al. (2008) observaram que a salinidade afetou linearmente o DC nas duas avaliações e os decréscimos relativos a $\mathrm{S} 1$ foram de 9,1 e $9,8 \%$ por incremento unitário de condutividade elétrica da água de irrigação aos 80 e 100 DAS, respectivamente.
Em geral, o excesso de sais na zona radicular das plantas exerce efeitos nocivos no crescimento, em que a hipótese que melhor explica este fato é a de que a salinidade excessiva reduz o crescimento e o desenvolvimento e causa até a morte das plantas em virtude do maior efeito osmótico externo à raiz e restrição ao fluxo de água do solo para as plantas, necessário para sobreviverem e produzirem em condições de estresse salino (RHOADES et al., 2000).

Notadamente, o efeito adverso da salinidade sobre a absorção e a utilização de nutrientes está relacionado com o aumento da pressão osmótica na solução do solo e com a acumulação de certos íons no tecido vegetal em concentrações tóxicas, ocasionando diminuição no crescimento do sistema radicular (POSTAL, 1990).

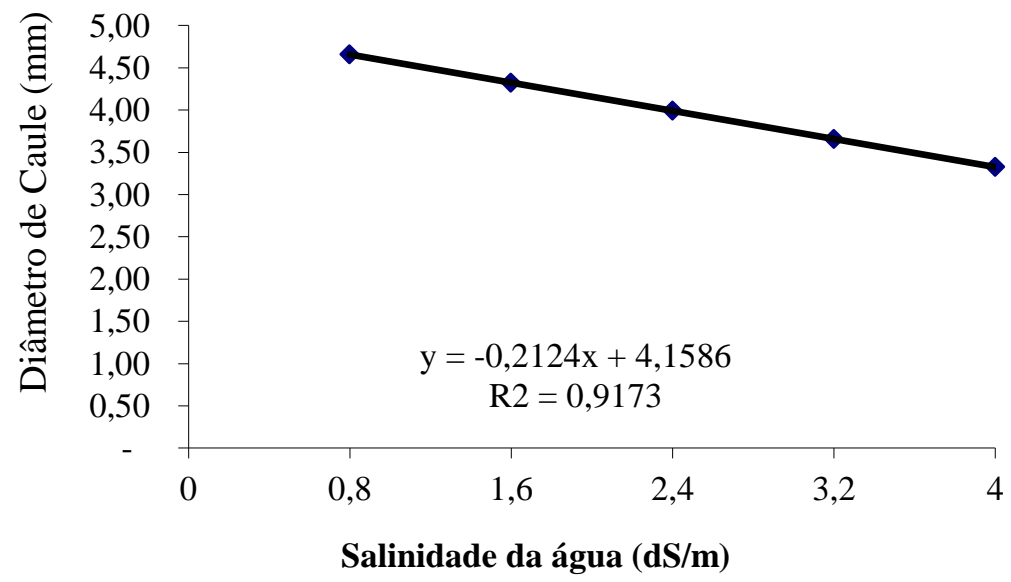

Figura 2: Diâmetro de caule da média das mudas de mamoeiro estudados, aos 30 dias após semeadura sob salinidade da água de irrigação $\left(\mathrm{dS} \mathrm{m}^{-1}\right)$. Pombal, PB, 2013. 
Ao analisarmos a altura das mudas de mamão (Figura 2), observa-se que o comportamento foi linear decrescente com o incremento unitário da salinidade da água (dSm-1), na ordem de 6,37\%, verificando-se que a melhor media foi de aproximadamente $16 \mathrm{~cm}$ de altura. Cavalcanti (2003), estudando o comportamento da mamona irrigada com águas contendo diferentes proporções de $\mathrm{Na}+$ e $\mathrm{Ca} 2+\mathrm{e}$ condutividade elétrica variando entre 0,7 e $4,7 \mathrm{dS}$ m-1, notou redução de 22,78\% na AP para a cultivar BRS-149 Nordestina; este valor, é maior que o observado no presente estudo, em decorrência de um efeito menos intenso do $\mathrm{NaCl}$, e a um período também menor de estudo ou, mesmo, por se tratar de uma cultivar diferente. Os dois estudos confirmam a redução da altura da planta com o aumento da salinidade da água de irrigação.

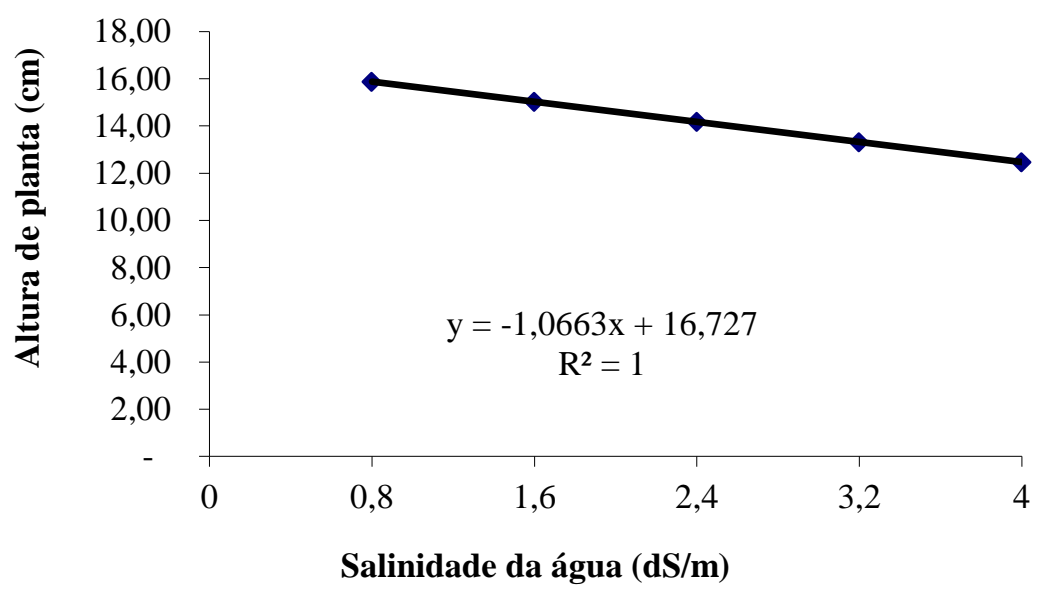

Figura 3: Altura de planta da média das mudas de mamoeiro estudados, aos 30 dias após semeadura sob salinidade da água de irrigação $\left(\mathrm{dS} \mathrm{m}{ }^{-1}\right)$. Pombal, PB, 2013.

Quanto a massa seca da parte aérea (Figura 4), também se verificou comportamento linear decrescente, com o aumento da salinidade da agua (dS m-1), observando uma redução de $10,41 \%$, dessa forma observa-se que o aumento da salinidade da agua proporcionou redução na formação de massa seca da parte aérea.

Os resultados obtidos por Morais et al. (2007) em cajueiro anão mostram que o aumento da concentração de $\mathrm{NaCl}$ na água de irrigação promove um aumento de $\mathrm{Na}+\mathrm{e} \mathrm{Cl}$ no tecido vegetal, reduzindo a produção de matéria seca de raízes e parte aérea.
O cloreto de sódio pode afetar negativamente a síntese e a translocação de hormônios das raízes para parte aérea, indispensáveis ao metabolismo foliar, o que resulta na perda de área foliar e consequentemente na matéria seca da parte aérea das plantas (TÁVORA; PEREIRA; HERNADEZ, 2001; TAIZ; ZEIGER, 2006). Além dos efeitos osmóticos da salinidade, o excesso de $\mathrm{Na}$ e $\mathrm{Cl}$ nos tecidos vegetais resulta em toxicidade iônica devido ao aumento nas relações $\mathrm{Na}+\mathrm{K}+, \mathrm{Na}+/ \mathrm{Ca}+2$ e Cl-/NO+3 (SHI; ZHU, 2002; SAQIB, AKHTAR; QURESHI, 2004; FERREIRA-SILVA et al., 2008).

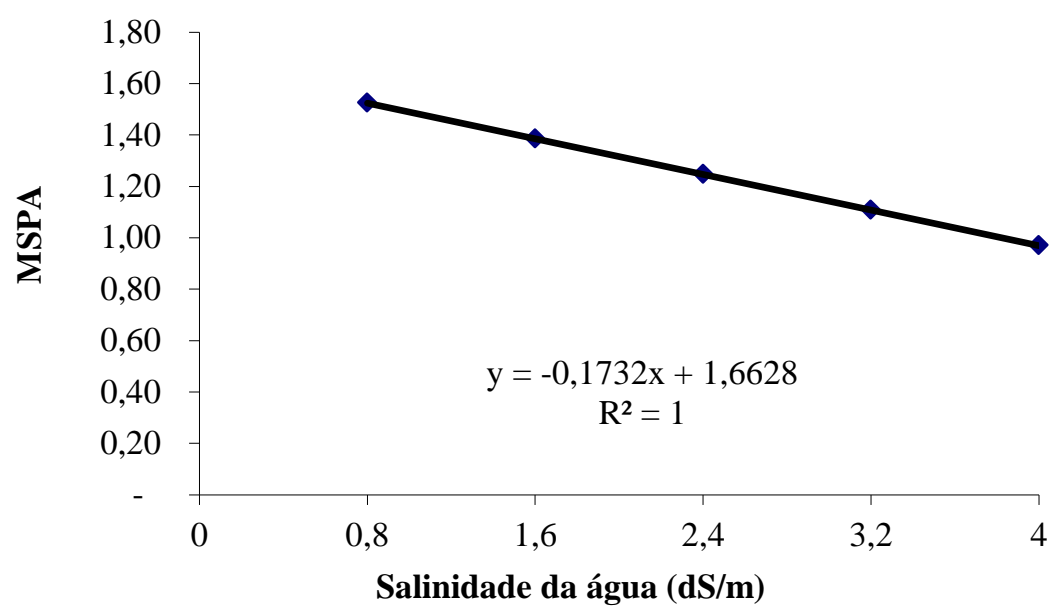

Figura 4: Matéria seca da parte aérea da média das mudas de mamoeiro estudados, aos 30 dias após semeadura sob salinidade da água de irrigação $\left(\mathrm{dS} \mathrm{m}{ }^{-1}\right)$. Pombal, PB, 2013. 


\section{CONCLUSÕES}

Tendo em vista o exposto no trabalho, a interpretação com base nos resultados obtidos, determinam que a salinidade reduz o crescimento das mudas de mamoeiro. Além disso, a altura de planta e diâmetro de caule foi afetado com o incremento unitário da salinidade da agua. Os objetivos propostos foram alcançados, visto que foram levantadas as informações necessárias para realização da pesquisa. Portanto, a variável que melhor expressa o efeito da salinidade nas mudas de mamoeiro é massa seca da parte aérea, por haver maior redução com aumento unitário da salinidade.

\section{REFERÊNCIAS BIBLIOGRÁFICAS}

Cavalcanti, M. L. F. Germinação e crescimento inicial da mamoneira irrigada com águas salinas. Campina Grande: UFCG,2003, 46p. Dissertação Mestrado

EPSTEIN, E.; BLOOM, A. J. Nutrição mineral de plantas: princípios e perspectivas. Londrina: Editora Planta. 403p, 2006.

FERREIRA-SILVA S. L.; SILVEIRA, J. A. G.; VOIGT, E. L.; SOARES, L. S. P.; VIÉGAS, R. A. Changes in physiological indicators associated with salt tolerance in two contrasting cashew rootstocks. Brazilian Journal Plant Physiology, Campinas, v. 20, n. 1, p. 51-59, 2008.

FERREIRA, D.F. Análises estatísticas por meio do Sisvar para Windows versão 4.0. In: REUNIÃO ANUAL DA REGIÃO BRASILEIRA DA SOCIEDADE INTERNACIONAL DE BIOMETRIA, 2000, São Carlos, SP. p.255-258.

LARCHER, W. Ecofisiologia Vegetal. São Carlos-SP. Ed. Rima Arts e Textos. 531 p. 2000.

MAAS, E.V.; HOFFMAN, G.J. Crop salt tolerance - current assessment. Journal of Irrigation and Drainage Division, New York, v.103, n.IR2, p.115-134, 1977

MARIN, S.L.D.; GOMES, J.A.; SALGADO, J.S Recomendação para a cultura

do mamoeiro cv. Solo do Estado do Espírito Santo. 3. ed., Vitória, s.ed., 1987.64 p.

MEDINA, J.C. Cultura. In: INSTITUTO DE TECNOLOGIA DE ALIMENTOS. Mamão. 2. ed., Campinas: Instituto Campineiro de Ensino Agrícola, 1989. p.1-177.

MEDINA, M.C. Cultura. In: ITAL. Mamão: cultura, matériaprima, processamento e aspectos econômicos. Campinas: ITAL, 1995. p.1-177. POPINIGIS, F. Fisiologia da semente. Brasília: AGIPLAN, 1985. 289p.

MORAIS, D. L.; VIÉGAS, R. A.; SILVA, L. M. M.; LIMA JUNIOR, A. R.; COSTA, R. C. L.; ROCHA, I. M. A.;
SILVEIRA, J. A. G. Acumulação de íons e metabolismo de $\mathrm{N}$ em cajueiro anão em meio salino. Revista Brasileira de Engenharia Agrícola e Ambiental, Campina Grande, v. 11 , n. 2, p. 125-133, 2007.

MUNNS, R.; et al. Avenues for increasing salt tolerance of crops, and the role of physiologically based selection traits. Plant and Soil, v. 247, p. 93-105, 2002

Postal, S. Saving water in agriculture. In; Brown, L. R.; Durning, A.; Flavin, C.; French, H.; Jacobson, J.; Lowe, M. (ed.). State of the world. New York: W. W. Norton, 1990. p.39-58.

Rhoades, J. D.; Kandiah, A.; Mashali, A. M.; Uso de águas salinas para produção agrícola. Campina Grande: UFPB. 2000,117p. Estudos da FAO, Irrigação e Drenagem, 48 revisado.

RHOADES, J.D.; KANDIAH, A.; MASHALI, Q.M. The use of saline waters for crop production. Rome: FAO, 1992. 133p. (Irrigation and Drainage Paper, 48).

RIBEIRO, M. R.; et al. Química dos solos salinos e sódicos. In: MELO, V. F.; ALLEONI, L. R. F. (ed.). Química e mineralogia do solo. Parte II - Aplicações Viçosa: Sociedade Brasileira de Ciência do Solo. p. 449-484, 2009

SAQIB, M.; AKHTAR, J.; QURESHI, R. H. Pot study on wheat growth in saline waterlogged compacted soil II. Root growth and leaf ionic relations. Soil and Tillage Research, Amsterdam, v. 77, n. 2, p. 179-187, 2004.

SILVA S.M.S.; ALVES A.N.; GHEYI H.R.; BELTRÃO N.E.M.; SEVERINO L.S.; SOARES F.A.L. Desenvolvimento e produção de duas cultivares de mamoneira sob estresse salino. Revista Brasileira de Engenharia Agrícola e Ambiental. v.12, n.4, p.335-342, 2008.

SHI, H. Z.; ZHU, J. K. Regulation of expression of the vacuolar $\mathrm{Na}+/ \mathrm{H}+$ antiporter gene AtNHX1 by salt stress and abscisic acid. Plant and Molecular Biology, Barcelona, v. 50, n. 3, p. 543-550, 2002.

TAIZ, L.; ZEIGER, E. Fisiologia vegetal. 3. ed. Porto Alegre: Artmed. 2006. 719 p.

TÁVORA, F. J. A. F.; PEREIRA, R. G.; HERNADEZ, F. F. F. Crescimento e relações hídricas em plantas de goiabeira submetidas a estresse salino com $\mathrm{Na} \mathrm{Cl}$. Revista Brasileira de Fruticultura,Jaboticabal, v. 23, n. 2, p. 441-446. 2001

WILLADINO, L.; CAMARA, T. R. Origen y naturaleza de los ambientes salinos. In: Reigosa, M. J.; Pedrol, N.; Sánchez, A. (ed.). La ecofisiología vegetal - Uma ciencia de síntesis. Madrid: Thompson, p.303-330, 2004. 